\title{
FOCAL MECHANISMS OF EARTHQUAKES OF SOUTHERN BAIKAL REGION AND NORTHERN MONGOLIA
}

\section{N.A. Radziminovich $\mathbb{\bigotimes}^{\otimes}$}

Institute of the Earth's Crust, Siberian Branch of the Russian Academy of Sciences, 128 Lermontov St, Irkutsk 664033, Russia

Buryat Branch of the Federal Research Centre of the Geophysical Survey, Russian Academy of Sciences, 6a Sakhyanova St, Ulan-Ude 670047, Buryatian Republic, Russia

ABSTRACT. The paper presents previously unpublished earthquake focal mechanism solutions for earthquakes which occurred in South Pribaikalye, Transbaikalia, Tuva and Northern Mongolia derived from the first-motion polarities of P-waves recorded by the Baikal, Buryat, Altai-Sayan networks of the Geophysical Survey RAS and Mongolian national network.

KEYWORDS: earthquake; focal mechanism; Transbaikalia; South Pribaikalye; Tuva; Mongolia

FUNDING: The work was supported by Ministry of Education and Science of Russia.

1. The data used in the work were obtained with large-scale research facilities «Seismic infrasound array for monitoring Arctic cryolitozone and continuous seismic monitoring of the Russian Federation, adjacent territories and the world».

2. The research was supported by the Russian Foundation for Basic Research, project 20-05-00357a.

3. This work involved the South Baikal instrumental complex for monitoring hazardous geodynamic processes in frame of the Centre of Geodynamics and Geochronology at the Institute of the Earth's Crust, Siberian Branch of the Russian Academy of Sciences (grant 075-15-2021-682).

\section{SHORT COMMUNICATION}

Correspondence: Natalia A. Radziminovich, nradzim@crust.irk.ru
Received: June 17, 2021

Revised: August 2, 2021

Accepted: August 12, 2021

FOR CITATION: Radziminovich N.A., 2021. Focal mechanisms of earthquakes of Southern Baikal Region and Northern Mongolia. Geodynamics \& Tectonophysics 12 (4), 902-908. doi:10.5800/GT-2021-12-4-0562 


\title{
МЕХАНИЗМЫ ОЧАГОВ ЗЕМЛЕТРЯСЕНИЙ ЮГА БАЙКАЛЬСКОГО РЕГИОНА И СЕВЕРНОЙ МОНГОЛИИ
}

\author{
Н.А. Радзиминович
}

Институт земной коры СО РАН, 664033, Иркутск, ул. Лермонтова, 128, Россия

Бурятский филиал ФИЦ ЕГС РАН, 670047, Улан-Удэ, ул. Сахьяновой, 6а, Республика Бурятия, Россия

АНнотАЦИЯ. В статье представлены не опубликованные ранее решения механизмов очагов землетрясений для территории Южного Прибайкалья, Забайкалья, Тувы и Северной Монголии, определенные по знакам вступлений продольных волн на станциях Байкальской, Бурятской, Алтае-Саянской сетей Геофизической службы РАН и Монгольской национальной сети.

КЛючЕВЫЕ СЛоВА: землетрясение; механизм очага; Забайкалье; Южное Прибайкалье; Тува; Монголия

ФИНАНСИРОВАНИЕ: Работа выполнена при поддержке:

1. Минобрнауки РФ (в рамках государственного задания № 075-01304-20) и с использованием данных, полученных на уникальной научной установке «Сейсмоинфразвуковой комплекс мониторинга Арктической криолитозоны и комплекс непрерывного сейсмического мониторинга Российской Федерации, сопредельных территорий и мира».

2. РФФИ (проект 20-05-00357a).

3. В работе задействовалось оборудование УНУ «Южно-Байкальский инструментальный комплекс для мониторинга опасных геодинамических процессов», входящий в состав ЦКП «Геодинамика и геохронология» Института земной коры СО РАН в рамках гранта № 075-15-2021-682.

\section{1. ВВЕДЕНИЕ}

Определение механизмов очагов землетрясений является одной из основных рутинных задач сейсмологии, решение которой обеспечивает оценку напряженно-деформированного состояния земной коры сейсмоактивных регионов. Основные закономерности поля напряжений для Байкальской рифтовой зоны и Монголии установлены в многочисленных публикациях [Misharina, 1972; Misharina et al., 1983; Khilko et al., 1985; Sherman, Dneprovsky, 1986; Petit et al., 1996; Melnikova et al., 2004; Bayasgalan et al., 2005; Melnikova, Radziminovich, 2007; Sankov et al., 2011; Parfeevets, Sankov, 2012; Kuchai, Kozina, 2015; Radziminovich et al., 2016; и др.]. Показано, что центральная часть Байкальской рифтовой системы находится в условиях растяжения земной коры при ориентации оси растяжения СЗ-ЮВ, а территория Монголии - под действием горизонтального сжатия, ориентированного Ю-С в западной части Монголии, ЮЗ-СВ в Гобийском Алтае и центральной части страны и субширотно в Восточной Монголии. В то же время область перехода между режимами сжатия и растяжения характеризуется разнообразием стрессрежимов. Кроме того, области Забайкалья и Северной Монголии мало обеспечены данными вследствие умеренного уровня сейсмичности по сравнению с рифтовой зоной.

В данной статье приводятся фокальные решения для землетрясений с $10.1 \leq \mathrm{K} \mathrm{p} \leq 12.9$, произошедших в Забайкалье, северной части Монголии, Туве, Тункинских впадинах и в Восточном Саяне. Механизмы очагов определены для периода времени 1996-2006 гг., когда обмен данными между разными сетями был затруднен вследствие аналоговой регистрации и перехода на цифровую запись. Большая часть полученных решений вошла в каталоги механизмов очагов землетрясений Байкальского региона, публикуемые в ежегоднике Геофизической службы ФИЦ ЕГС РАН «Землетрясения Северной Евразии». В настоящую статью вошли неопубликованные решения за период 1996-1999 гг., а также показаны решения за 2000-2006 гг., которые приводились в Supplementary Materials в статье [Radziminovich et al., 2016], однако из-за невысокого энергетического класса не вошли в основную таблицу статьи и не были показаны на карте «Map of focal mechanisms of earthquakes in Mongolia and its surroundings» [Radziminovich et al., 2011]. Полученные результаты восполняют базу данных механизмов и могут быть использованы при сейсмотектоническом анализе.

\section{2. ДАННЫЕ И МЕТОД}

Для землетрясений умеренной силы одним из основных методов определения механизма является метод полярности первых вступлений. Данный метод широко применялся и применяется до сих пор для землетрясений Байкальского региона (например [Vvedenskaya, Balakina, 1960; Balakina et al., 1972; Misharina, 1972; Misharina, Solonenko, 1977; Solonenko et al., 1993; Melnikova, Radziminovich, 1998]). При использовании этого метода критичным является расположение станций вокруг эпицентра для обеспечения всех квадрантов знаками. Для землетрясений с эпицентрами в приграничной зоне контролирующей сети расположение станций во многих случаях оказывается односторонним, и требуется привлечение сейсмограмм с соседних 
сетей. Подобная ситуация характерна для землетрясений Южного Прибайкалья и Забайкалья. В последнее десятилетие, когда все регистрирующие сети перешли на цифровую регистрацию, эта проблема решена за счет обмена данными по сети Интернет. Однако в период аналоговой регистрации и в период перехода на цифровую запись (90-е гг. прошлого столетия и начало 2000-х гг.) была необходимость работать с сейсмограммами непосредственно в архивах филиалов Геофизической службы. С целью обеспечения непрерывности базы данных по механизмам очагов землетрясений Байкальского региона за такой период были просмотрены сейсмограммы Байкальского и Бурятского филиалов (архив в г. Иркутске), Алтае-Саянского филиала (архив в г. Новосибирске) и Монгольской национальной сети (архив в г. Улан-Баторе). Полярность приборов проверялась при анализе знаков вступлений на станциях от сильных далеких землетрясений. Углы выхода волн рассчитывались для среднего значения глубины очагов землетрясений 15 км в предположении однородной однослойной скоростной модели среды.

\section{3. РЕЗУЛЬТАТЫ И ОБСУЖДЕНИЕ}

Механизмы очагов представлены на рис. 1 и в табл. 1. Необходимо отметить, что рассматриваемые землетрясения имели невысокий энергетический класс, что затрудняет интерпретацию результатов. Рассмотрим кратко полученные решения для отдельных районов.

Для Западного Забайкалья добавилось два решения (№ 5, 18), характеризующихся сжатием, ориентированным 44-46 ${ }^{\circ}$ Землетрясение с эпицентром в хр. ЦаганХурт было вызвано сдвиговой подвижкой, а в хр. Цаган-Дабан - взбросом или надвигом по плоскостям северо-западной ориентации. Анализ фокальных механизмов землетрясений Забайкалья показал, что земная кора этого региона находится в условиях сдвига и сдвига с растяжением. Растяжение более проявлено вблизи Южно-Байкальской впадины, тогда как далее к востоку нарастает роль горизонтального сжатия. Однако сейсмогеологические данные свидетельствуют о взбросо-сдвиговых деформациях уже в пределах Гусиноозерской и Оронгойских впадин [Smekalin et al., 2019], чему не противоречат представленные механизмы очагов.

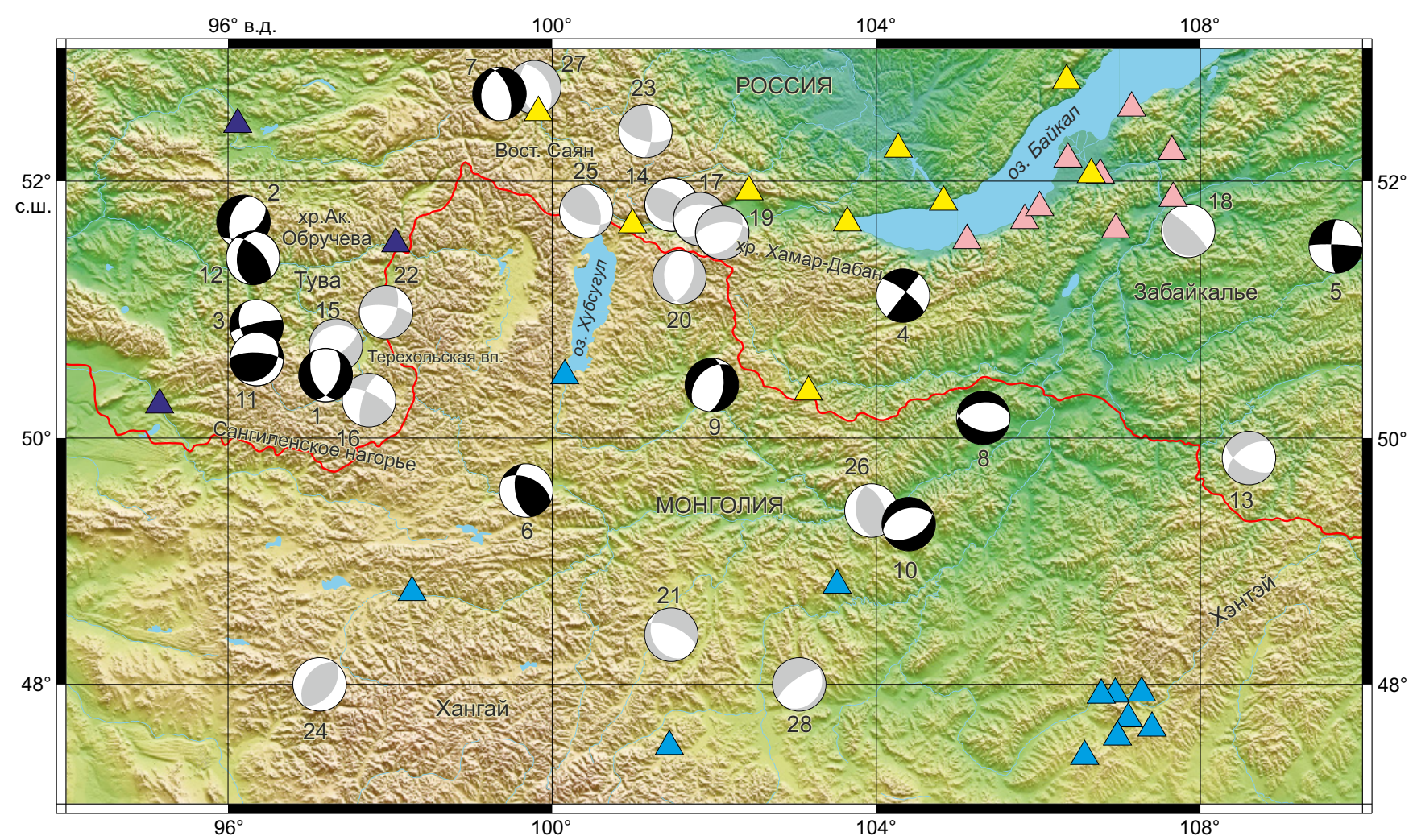

Рис. 1. Механизмы очагов землетрясений в проекции нижней полусферы.

Серым цветом показаны решения из Supplementary Materials в [Radziminovich et al., 2016], черным цветом - новые определения. Номера стереограмм соответствуют номерам землетрясений в табл. 1. Треугольники желтого цвета - сейсмические станции Байкальского филиала ФИЦ ЕГС РАН, розового - Бурятского филиала, темно-синего - Алтае-Саянского, голубого Монгольской сети станций. В обработке также использовались записи станций, расположенных за пределами указанной координатной сетки.

Fig.1. Earthquake focal mechanisms in the lower hemisphere projection.

The solutions from Supplementary Materials in [Radziminovich et al., 2016] are in gray, newly determined are in black. Stereogram numbers correspond to earthquake numbers in Table 1. The yellow triangles show seismic stations of the Baikal Branch of the FRC GS RAS, the pink triangles - those of the Buryat Branch, dark-blue - of the Altai-Sayan Brunch, blue - of the Mongolian network. The processing also involved the records made by the stations located beyond the network reported. 
Таблица 1. Механизмы очагов землетрясений

Table 1. Earthquake focal mechanisms

\begin{tabular}{|c|c|c|c|c|c|c|c|c|c|c|c|c|c|c|c|c|c|c|}
\hline № & Дата & Время & с.ш. & в.д. & K & $\mathrm{T} \mathrm{pl}$ & $\mathrm{T}$ az & $\mathrm{N} \mathrm{pl}$ & $\mathrm{N}$ az & $\mathrm{P} \mathrm{pl}$ & $\mathrm{P}$ az & STK & DIP & SLIP & STK & DIP & SLIP & Q \\
\hline 1 & $1996 / 02 / 21$ & $02: 44$ & 50.66 & 97.34 & 11.3 & 1 & 89 & 25 & 179 & 65 & 357 & 22 & 51 & -57 & 156 & 49 & -124 & $\mathrm{a}$ \\
\hline 2 & $1996 / 05 / 17$ & 03:00 & 51.69 & 96.19 & 11.2 & 1 & 126 & 22 & 216 & 68 & 33 & 195 & 48 & -120 & 56 & 50 & -61 & $\mathrm{a}$ \\
\hline 3 & $1996 / 09 / 20$ & 05:04 & 50.88 & 96.35 & 12.1 & 41 & 129 & 39 & 265 & 24 & 16 & 154 & 41 & 164 & 256 & 80 & 50 & $\mathrm{c}$ \\
\hline 4 & $1996 / 09 / 21$ & $20: 34$ & 51.12 & 104.33 & 10.0 & 10 & 264 & 76 & 38 & 10 & 172 & 308 & 76 & 0 & 38 & 90 & 166 & $\mathrm{c}$ \\
\hline 5 & $1996 / 11 / 02$ & $21: 46$ & 51.50 & 109.67 & 11.1 & 14 & 137 & 75 & 293 & 6 & 46 & 181 & 76 & 174 & 272 & 84 & 14 & $\mathrm{~b}$ \\
\hline 6 & $1998 / 02 / 04$ & 01:22 & 49.58 & 99.68 & 11.3 & 58 & 138 & 32 & 326 & 3 & 234 & 170 & 56 & 129 & 295 & 50 & 47 & $\mathrm{c}$ \\
\hline 7 & $1998 / 04 / 21$ & $8: 11$ & 52.66 & 99.35 & 11.8 & 14 & 82 & 12 & 349 & 71 & 219 & 189 & 33 & -67 & 342 & 60 & -104 & $\mathrm{c}$ \\
\hline 8 & $1998 / 05 / 16$ & $23: 42$ & 50.16 & 105.32 & 11.4 & 4 & 184 & 10 & 275 & 79 & 72 & 103 & 50 & -77 & 263 & 42 & -105 & $\mathrm{a}$ \\
\hline 9 & $1998 / 06 / 21$ & $18: 57$ & 50.42 & 101.97 & 10.5 & 6 & 113 & 19 & 21 & 70 & 220 & 223 & 42 & -61 & 6 & 54 & -114 & $\mathrm{a}$ \\
\hline 10 & $1998 / 09 / 25$ & $01: 55$ & 49.31 & 104.40 & 12.2 & 4 & 158 & 6 & 68 & 83 & 284 & 63 & 49 & -97 & 254 & 41 & -82 & $\mathrm{a}$ \\
\hline 11 & $1998 / 12 / 13$ & 09:04 & 50.67 & 96.24 & 12.9 & 59 & 214 & 21 & 84 & 22 & 345 & 41 & 30 & 43 & 272 & 70 & 113 & $\mathrm{~b}$ \\
\hline 12 & $1999 / 04 / 12$ & $18: 56$ & 51.54 & 96.26 & 11.0 & 63 & 181 & 24 & 334 & 11 & 69 & 319 & 60 & 62 & 186 & 40 & 129 & $\mathrm{a}$ \\
\hline 13 & $1999 / 06 / 08$ & 11:39 & 49.84 & 108.60 & 10.1 & 3 & 178 & 41 & 271 & 49 & 85 & 120 & 60 & -42 & 234 & 55 & -142 & $\mathrm{c}$ \\
\hline 14 & $2000 / 04 / 22$ & $04: 20$ & 51.73 & 101.82 & 10.2 & 74 & 245 & 9 & 120 & 13 & 28 & 105 & 33 & 72 & 306 & 59 & 101 & $\mathrm{a}$ \\
\hline 15 & $2000 / 04 / 22$ & $17: 48$ & 50.73 & 97.33 & 12.0 & 19 & 151 & 6 & 59 & 70 & 311 & 56 & 64 & -97 & 252 & 27 & -76 & $\mathrm{c}$ \\
\hline 16 & $2000 / 08 / 07$ & 19:59 & 50.30 & 97.74 & 10.7 & 30 & 157 & 60 & 339 & 1 & 247 & 198 & 70 & 158 & 296 & 69 & 21 & $\mathrm{c}$ \\
\hline 17 & $2002 / 03 / 06$ & $15: 59$ & 51.69 & 102.03 & 10.1 & 4 & 159 & 19 & 68 & 71 & 261 & 52 & 52 & -114 & 268 & 44 & -62 & $\mathrm{~b}$ \\
\hline 18 & $2002 / 03 / 10$ & 06:38 & 51.62 & 107.85 & 10.2 & 55 & 224 & 0 & 314 & 35 & 44 & 314 & 80 & 90 & 135 & 10 & 91 & $\mathrm{a}$ \\
\hline 19 & $2002 / 04 / 03$ & 06:30 & 51.61 & 102.15 & 10.6 & 10 & 336 & 21 & 70 & 67 & 223 & 43 & 40 & -124 & 264 & 58 & -65 & $\mathrm{a}$ \\
\hline 20 & $2003 / 01 / 09$ & 02:25 & 51.26 & 101.57 & 11.0 & 4 & 97 & 14 & 188 & 76 & 353 & 20 & 50 & -72 & 173 & 43 & -110 & $\mathrm{c}$ \\
\hline 21 & $2003 / 01 / 28$ & $20: 55$ & 48.41 & 101.47 & 11.3 & 19 & 36 & 15 & 301 & 65 & 176 & 294 & 66 & -106 & 149 & 29 & -58 & $\mathrm{~b}$ \\
\hline 22 & $2003 / 11 / 20$ & 03:26 & 50.99 & 97.95 & 10.7 & 6 & 330 & 52 & 68 & 37 & 236 & 20 & 60 & -156 & 277 & 69 & -32 & $\mathrm{~b}$ \\
\hline 23 & $2003 / 11 / 20$ & $23: 42$ & 52.38 & 101.15 & 11.5 & 37 & 320 & 52 & 153 & 6 & 55 & 2 & 70 & 148 & 104 & 60 & 23 & $\mathrm{~b}$ \\
\hline 24 & $2003 / 11 / 29$ & 03:39 & 48.00 & 97.13 & 11.4 & 88 & 3 & 2 & 217 & 1 & 127 & 38 & 46 & 92 & 215 & 44 & 88 & $\mathrm{a}$ \\
\hline 25 & $2004 / 12 / 12$ & $08: 59$ & 51.77 & 100.42 & 11.7 & 61 & 323 & 29 & 134 & 4 & 226 & 111 & 55 & 54 & 343 & 48 & 130 & $\mathrm{a}$ \\
\hline 26 & $2005 / 08 / 30$ & 15:06 & 49.42 & 103.94 & 11.0 & 82 & 199 & 7 & 345 & 5 & 76 & 340 & 50 & 81 & 174 & 41 & 101 & $\mathrm{a}$ \\
\hline 27 & $2005 / 11 / 16$ & $22: 47$ & 52.71 & 99.78 & 10.5 & 0 & 249 & 10 & 339 & 80 & 159 & 329 & 46 & -104 & 169 & 46 & -76 & $\mathrm{a}$ \\
\hline 28 & $2006 / 03 / 06$ & 19:10 & 48.00 & 103.05 & 11.4 & 26 & 320 & 6 & 53 & 63 & 156 & 35 & 20 & -109 & 235 & 71 & -83 & $\mathrm{c}$ \\
\hline
\end{tabular}

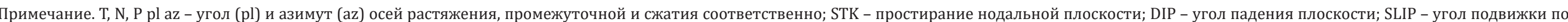
плоскости; Q - качество решения, оцененное по отклонению угла осей T, N и P: a - менее $10^{\circ}$, b - от 10 до $15^{\circ}$, с - от 15 до $30^{\circ}$.

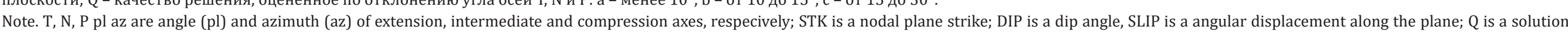
quality estimated from $\mathrm{T}, \mathrm{N}$ and $\mathrm{P}$ axis deviation angles: a - less than $10^{\circ}, \mathrm{b}$ - from $10^{\circ}$ to $15^{\circ}, \mathrm{c}$ - from $15^{\circ}$ to $30^{\circ}$. 
Для северной части Центральной Монголии (хр. Бутээлин, Бурэнгийн, Хэнтэй) на весомый вклад сдвиговой компоненты в общую деформацию указывают механизмы очагов сильнейших землетрясений, в то же время многие фокальные механизмы более слабых землетрясений, в том числе и новые определения, указывают на сбросовые смещения в очагах. Судя по энергетической представительности землетрясений с разными типами механизмов, можно предположить подчиненный характер растяжения по отношению к сдвиговой деформации [Radziminovich et al., 2017].

Механизм сдвиго-взбросового типа (№ 6) был определен для землетрясения с эпицентром на восточном окончании Болнайского разлома, в районе Бугсэйнгольской палеосейсмодислокации с аналогичным типом смещений [Khilko et al., 1985]. Землетрясение, произошедшее в хр. Хамар-Дабан в южном обрамлении оз. Байкал (№ 4), было сдвигового типа. Примечательно то, что южное замыкание Южно-Байкальской впадины характеризуется режимом транстенсии [Radziminovich et al., 2006], т.е. очевидно, что сдвиговая компонента и в близлежащих очагах обусловлена не локальными причинами. К западу от Южно-Байкальской впадины, в Тункинском сегменте Байкальской рифтовой системы, усиливающееся сжатие приводит к режиму транспрессии или сдвига (например [Arzhannikova et al., 2007; Parfeevets, Sankov, 2006; Delouis et al., 2002]), однако взбросовая и сдвиговая кинематика смещений по разломам более выражена в западной части впадин, что подтверждается механизмами очагов под № 14 и 25 . Землетрясения под № 17 и 19 со сбросовым типом фокальных механизмов произошли в южной части Тункинской впадины и в ее южном борту и, вероятно, связаны со скрытым Байкало-Мондинским разломом [Arzhannikova et al., 2007].

Известно, что северная часть Хубсугульской впадины находится в условиях растяжения [Misharina et al., 1983; Khilko et al., 1985], при этом территория к востоку от озера остается малоизученной. Механизмы очагов землетрясений (№ 9, 20), произошедших на этой территории, свидетельствуют о сбросообразовании по плоскостям меридиональной и север-северо-восточной ориентации. Раздвиговое перемещение по меридиональному разрыву было получено при моделировании напряженного состояния в области Т-образного сочленения структур Хубсугула и ограничивающего их с севера Иххорогол-Мондинского разлома, что соответствует области пассивного раздвижения блоков в районе сочленения разрывов [Sankov et al., 2004].

Поднятие Восточного Саяна в настоящее время находится в сдвиговом режиме с преобладающим влиянием север-северо-восточного сжатия (например [Delouis et al., 2002; Radziminovich et al., 2016]), однако землетрясения под № 7, 27 являются сбросами. Их эпицентры приурочены к зоне Окинского локального (вторичного) растяжения, вызванного смещением блока земной коры между основными сдвиговыми разломами, ограничивающими Окинское плоскогорье [Arzhannikova et al., 2011]. Примечательно то, что ориентация плоскостей в механизмах совпадает с простиранием сегментов разломов сбросовой кинематики, выявленных по геолого-геоморфологическим данным.

Землетрясения под № 2,12 в хр. Обручева имеют разнонаправленные подвижки в очагах. Вообще территория Тувы характеризуется условиями преобладающего сжатия, так что сбросовый тип смещений в очагах здесь встречается редко. Оба этих события произошли вблизи очагов Тувинских толчков 2011-2012 гг. с $\mathrm{M}_{\mathrm{w}} 6.7$, вызванных сдвиговой и взбросовой подвижками по Каахемскому разлому [Emanov et al., 2018]. Подобные же механизмы получены и для землетрясений с № 3, 11 в северных отрогах Сангиленского нагорья. Другой тип механизмов - с наличием сбросовой компоненты - более характерен для землетрясений Бусийнгольской и Терехольской впадин и их горного обрамления (№ 1,15 , $16,22)$. Сдвиги и сбросы в очагах землетрясений являются основными кинематическими типами фокальных решений для Бусийнгольской активизации в 2004 г., сильнейший толчок которой 27.12.1991 г. с MS6.5 был «чистым» сдвигом [Emanov et al., 2010].

\section{4. ЗАКЛЮЧЕНИЕ}

Представленные решения механизмов очагов значительно дополняют банк данных для юга Прибайкалья и Забайкалья, Тувы и Северной Монголии. Краткий анализ результатов показал, что механизмы очагов соответствуют установленным ранее закономерностям напряженно-деформированного состояния этого региона и подтверждают некоторые локальные особенности, как, например, проявление сбросовых подвижек в региональном поле сжатия или сдвига.

\section{5. БЛАГОДАРНОСТИ}

Для определения механизмов очагов были просмотрены аналоговые и цифровые сейсмограммы национальной сети сейсмостанций Монголии (Институт астрономии и геофизики МАН), Байкальской, Бурятской и Алтае-Саянской сети ФИЦ ЕГС РАН. Автор выражает благодарность сотрудникам перечисленных организаций за помощь в получении данных.

\section{6. ЛИТЕРАТУРА / REFERENCES}

Arzhannikova A., Arzhannikov S., Jolivet M., Vassallo R., Chauvet A., 2011. Pliocene to Quaternary deformation in South East Sayan (Siberia): Initiation of the Tertiary Compressive Phase in the Southern Termination of the Baikal Rift System. Journal of Asian Earth Sciences 40 (2), 581594. https://doi.org/10.1016/j.jseaes.2010.10.011.

Arzhannikova A.V., Melnikova V.I., Radziminovich N.A., 2007. Late Quaternary and Current Deformation in the Western Tunka System of Basins: Evidence from Structural Geomorphology and Seismology. Russian Geology and Geophysics 48 (4), 305-311. https://doi.org/10.1016/j.rgg. 2007.03.001.

Balakina L.M., Vvedenskaya A.V., Golubeva N.V., Misharina L.A., Shirokova E.I., 1972. Elastic Stress Field of the 
Earth and Earthquake Focal Mechanisms. Nauka, Moscow, 191 p. (in Russian) [Балакина Л.М., Введенская А.В., Голубева Н.В., Мишарина Л.А., Широкова Е.И. Поле упругих напряжений Земли и механизм очагов землетрясений. М.: Наука, 1972. 191 с.].

Bayasgalan A., Jackson J., MacKenzi D., 2005. Lithosphere Rheology and Active Tectonics in Mongolia: Relations between Earthquake Source Parameters, Gravity and GPS Measurements. Geophysical Journal International 163 (3), 11511179. https://doi.org/10.1111/j.1365-246X.2005.02764.x.

Delouis B., Deverchere J., Melnikova V., Radziminovich N., Loncke L., Larroque C., Ritz J.F., Sankov V., 2002. A Reappraisal of the 1950 (Mw 6.9) Mondy Earthquake, Siberia, and Its Relationship to the Strain Pattern at the South-Western End of the Baikal Rift Zone. Terra Nova 14 (6), 491-500. https://doi.org/10.1046/j.1365-3121.2002.00445.x.

Emanov A.F., Emanov A.A., Fateev A.V., Podkorytova V.G., Gilyova N.A., Masalsky O.K., 2018. Aftershocks of the Tuva Earthquakes 27.12.2011, ML=6.7 and 26.02.2012, ML=6.8 (Tuva Republic). Earthquakes of Northern Eurasia (2012). Vol. 21. FRC GS RAS, Obninsk, p. 302-312 (in Russian) [Еманов А.Ф., Еманов А.А., Фатеев А.В., Подкорытова В.Г., Гилёва Н.А., Масальский О.К. Афтершоки Тувинского-І землетрясения 27 декабря 2011 г. с ML=6.7 и ТувинскогоII - 26 февраля 2012 г. с ML=6.8 (Республика Тува) // Землетрясения Северной Евразии (2012 г.). Обнинск: ФИЦ ЕГС РАН, 2018. Вып. 21. С. 302-312].

Emanov A.F., Leskova E.V., Filina A.G., Emanov A.A., Fateev A.V., 2010. Earthquakes of Northern Eurasia (2004). GS RAS, Obninsk, p. 142-152 (in Russian) [Еманов А.Ф., Лескова Е.В., Филина А.Г., Еманов А.А., Фатеев А.В. Алтай и Саяны // Землетрясения Северной Евразии (2004 г.). Обнинск: ГС РАН, 2010. С. 142-152].

Khilko S.D., Kurushin R.A., Kochetkov V.M., Misharina L.A., Melnikova V.I., Gilyova N.A., Lastochkin S.V., Baljinnyam I., Monkhoo D., 1985. Earthquakes and Basis for Seismic Zoning of Mongolia. Nauka, Moscow, 224 p. (in Russian) [Хилько С.Д., Курушин Р.А., Кочетков В.М., Мишарина Л.А., Мельникова В.И., Гилева Н.А., Ласточкин С.В., Балжинням И., Монхоо Д. Землетрясения и основы сейсмического районирования Монголии. М.: Наука, 1985. 224 с.].

Kuchai O.A., Kozina M.E., 2015. Regional Features of Seismotectonic Deformations in East Asia Based on Earthquake Focal Mechanisms and Their Use for Geodynamic Zoning. Russian Geology and Geophysics 56 (10), 14911499. https://doi.org/10.1016/j.rgg.2015.09.011.

Melnikova V.I., Radziminovich N.A., 1998. Focal Mechanisms of the Earthquakes of the Baikal Region for 19911996. Russian Geology and Geophysics 39 (11), 1598-1607 (in Russian) [Мельникова В.И., Радзиминович Н.А. Механизм очагов землетрясений Байкальского региона за 1991-1996 гг. // Геология и геофизика. 1998. Т. 39. № 11. C. 1598-1607].

Melnikova V.I., Radziminovich N.A., 2007. Parameters of Seismotectonic Deformations of the Earth's Crust in the Baikal Rift Zone Based on Seismological Data. Doklady Earth Sciences 416, 1137-1139. https://doi.org/10.1134/S102 $8334 X 07070355$.
Melnikova V.I., Radziminovich N.A., Adyaa M., 2004. Mechanisms of Earthquake Foci and Seismotectonic Deformations of the Mongolia Region. In: V.I. Dzhurik, T. Dugarmaa (Eds), Complex Geophysical and Seismological Investigations in Mongolia. Ulaanbaatar-Irkutsk: RCAG MAN, p. 165-170.

Misharina L.A., 1972. Stresses in the Sources of Earthquakes in the Mongolia-Baikal zone. In: Elastic Stress Field of the Earth and Earthquake Focal Mechanisms. Nauka, Moscow, p. 161-171 (in Russian) [Мишарина Л.А. Напряжения в очагах землетрясений Монголо-Байкальской зоны // Поле упругих напряжений Земли и механизм очагов землетрясений. М.: Наука, 1972. С. 161-171].

Misharina L.A., Melnikova V.I., Baljinnyam I., 1983. Southwestern Boundary of the Baikal Rift Zone from the Data on Earthquake Focal Mechanisms. Volcanology and Seismology 2, 74-83 (in Russian) [Мишарина Л.А., Мельникова В.И., Балжинням И. Юго-западная граница Байкальской рифтовой зоны по данным о механизме очагов землетрясений // Вулканология и сейсмология. 1983. № 2. C. 74-83].

Misharina L.A., Solonenko N.V., 1977. Earthquake Focal Mechanisms and Stressed State of the Earth's Crust in the Baikal Rift Zone. In: N.A. Logachev, N.A. Florensov, A Role of Rifting in Geological History of the Earth. Nauka, Novosibirsk, p. 120-125 (in Russian) [Мишарина Л.А., Солоненко Н.В. Механизм очагов землетрясений и напряженное состояние земной коры в Байкальской рифтовой зоне // Роль рифтогенеза в геологической истории Земли / Ред. Н.А. Логачев, Н.А. Флоренсов. Новосибирск: Наука, 1977. С. 120-125].

Parfeevets A.V., Sankov V.A., 2006. Stress State of the Crust and Geodynamics of the Southwestern Part of the Baikal Rift System. GEO, Novosibirsk, 151 p. (in Russian) [Парфеeвец А.В., Саньков В.А. Напряженное состояние земной коры и геодинамика юго-западной части Байкальской рифтовой системы. Новосибирск: Гео, 2006. 151 с.].

Parfeevets A.V., Sankov V.A., 2012. Late Cenozoic Tectonic Stress Fields of the Mongolian Microplate. Comptes Rendus Geoscience 344 (3-4), 227-238. https://doi.org/ 10.1016/j.crte.2011.09.009.

Petit C., Déverchère J., Houdry F., Sankov V.A., Melnikova V.I., Delvaux D., 1996. Present-Day Stress Field Changes along the Baikal Rift and Tectonic Implication. Tectonics 15 (6), 1171-1191. https://doi.org/10.1029/96TC00624.

Radziminovich N.A., Bayar G., Miroshnichenko A.I., Demberel S., Ulziibat M., Ganzorig D., Lukhnev A.V., 2016. Focal Mechanisms of Earthquakes and Stress Field of the Crust in Mongolia and Its Surroundings. Geodynamics \& Tectonophysics 7 (1), 23-38 (in Russian) [Радзиминович Н.А., Баяр Г., Мирошниченко А.И., Дэмбэрэл С., Ульзибат М., Ганзориг Д., Лухнев А.В. Механизмы очагов землетрясений и поле напряжений Монголии и прилегающих территорий // Геодинамика и тектонофизика. 2016. Т. 7. № 1. C. 23-38. https://doi.org/10.5800/GT-2016-7-1-0195.

Radziminovich N.A., Bayar G., Ulzibait M., Ganzorig D., Demberel S., 2017. Seismicity, Earthquake Focal Mechanisms and Stressed-Strained State of the Earth's Crust of the Central Mongolia. In: D.P. Gladkochub (Ed.), Hazardous 
Geological Processes and Natural Hazard Forecasting in Central Mongolia. ISU Publishing House, Irkutsk, p. 53-61 (in Russian) [Радзиминович Н.А., Баяр Г., Ульзибайт М., Ганзориг Д., Демберел С. Сейсмичность, механизмы очагов землетрясений и напряженно-деформированное состояние земной коры Центральной Монголии // Опасные геологические процессы и прогнозирование чрезвычайных ситуаций природного характера на территории Центральной Монголии / Ред. Д.П. Гладкочуб. Иркутск: Изд-во ИГУ, 2017. С. 53-61].

Radziminovich N.A., Demberel S., Bayar G., 2011. Map of the Focal Mechanisms of Earthquakes in Mongolia. In: Proceedings of the IX Joint Russian-Mongolian Conference on Astronomy and Geophysics (October 10-12, 2011). ISTP SB RAS, Irkutsk, p. 27-28.

Radziminovich N.A., Melnikova V.I., Sankov V.A., Levi K.G., 2006. Seismicity and Seismotectonic Deformations of the Crust in the Southern Baikal Basin. Izvestiya. Physics of the Solid Earth 42 (11), 904-920. https://doi.org/10.1134/S1 069351306110048.

Sankov V.A., Miroshnichenko A.I., Parfeevets A.V., Arzhannikova A.V., Lukhnev A.V., 2004. Late Cenozoic State of Stress in the Earth's Crust of the Khubsugul Region (Northern Mongolia): Field and Experimental Evidence. Geotectonics 2, 78-90 (in Russian) [Саньков В.А., Мирошниченко А.И., Парфеевец А.В., Аржанникова А.В., Лухнев А.В. Позднекайнозойское напряженное состояние земной коры Прихубсугулья (Северная Монголия) по натурным и экспериментальным данным // Геотектоника. 2004. № 2. C. 78-90].

Sankov V.A., Parfeevets A.V., Lukhnev A.V., Miroshnichenko A.I., Ashurkov S.V., 2011. Late Cenozoic Geodynamics and
Mechanical Coupling of Crustal and Upper Mantle Deformations in the Mongolia-Siberia Mobile Area. Geotectonics 45, 378. https://doi.org/10.1134/S0016852111050049.

Sherman S.I., Dneprovsky Yu.I., 1986. New Map of Stress Fields of the Baikal Rift Zone Based on Geological and Structural Data. Doklady of the USSR Academy of Sciences 287 (4), 943-947 (in Russian) [Шерман С.И., Днепровский Ю.И. Новая карта полей напряжений Байкальской рифтовой зоны по геолого-структурным данным // Доклады AH CCCP. 1986. T. 287. № 4. C. 943-947].

Smekalin O.P., Chipizubov A.V., Radziminovich N.A., Imaev V.S., 2019. Seismic Activity of the Khambinskii Fault (Southwestern Transbaikalia). Russian Geology and Geophysics 60 (6), 690-703. https://doi.org/10.15372/RGG 2019034.

Solonenko A.V., Solonenko N.V., Melnikova V.I., Kozmin B.M., Kuchai O.A., Sukhanova S.S., 1993. Stresses and Displacements in the Sources of Earthquakes in Siberia and Mongolia. In: Seismicity and Seismic Zoning of North Eurasia. Vol. 1. P. 113-122 (in Russian) [Солоненко А.В., Солоненко Н.В., Мельникова В.И., Козьмин Б.М., Кучай О.А., Суханова С.С. Напряжения и подвижки в очагах землетрясений Сибири и Монголии // Сейсмичность и сейсмическое районирование Северной Евразии. 1993. Вып. 1. С. 113-122].

Vvedenskaya A.V., Balakina L.M., 1960. Technique and Results of Determination of Stresses in the Sources of Earthquakes in Pribaikalye and Mongolia. Bulletin of the Committee on Seismology 10, 73-84 (in Russian) [Введенская A.В., Балакина Л.М. Методика и результаты определения напряжений, действующих в очагах землетрясений Прибайкалья и Монголии // Бюллетень Совета по сейсмологии. 1960. № 10. С. 73-84]. 